\title{
The rationale for the current boom in anti-TNF $\alpha$ treatment. Is there an effective means to define therapeutic targets for drugs that provide all the benefits of anti-TNF $\alpha$ and minimise hazards?
}

\author{
Marc Feldmann, Jan Bondeson, Fionula M Brennan, Brian M J Foxwell, \\ Ravinder N Maini
}

\begin{abstract}
Progress in understanding mechanisms of disease are necessary to usher in major changes in treatment. A new era in rheumatoid arthritis (RA) and related chronic autoimmune/inflammatory diseases is now beginning, with a variety of anti-TNF $\alpha$ treatments licensed for use in both RA and Crohn's disease. The rationale for this new treatment lies in an understanding that cytokines are critical, rate limiting molecules lying at the heart of the chronic autoimmune/inflammatory disease process. This understanding was developed from the critical evaluation of a hypothesis that was proposed linking cytokines, antigen presentation and autoimmunity in 1983. Detailed analysis focusing on the major site of the disease, the rheumatoid synovium was essential to developing indications that blockade of TNF $\alpha$ might be efficacious. This clue was validated using anti-TNF $\alpha$ treatment of an animal model of RA, murine collagen induced arthritis, and by immunohistochemical demonstration of upregulated TNF and TNF-R expression in the synovium. With this three pronged rationale, the authors were able to convince Centocor, Inc, which had developed a chimaeric anti-TNF $\alpha$ antibody for use in sepsis, to work with them to test the concept that TNF $\alpha$ blockade would be beneficial in RA. With the success of that first trial, other companies have subsequently tested their anti-TNF strategies successfully. Current interests extend to understanding the processes that regulate TNF production in the rheumatoid joint. Progress in this area is discussed, using adenoviruses to infect normal macrophages and rheumatoid synovium.

(Ann Rheum Dis 1999;58:(Suppl I) I27-I31)
\end{abstract}

Cytokines are protein mediators that are intimately involved in all biological processes, including cell growth, differentiation, inflammation, immunity, etc. Their biochemical characterisation began in the 1970s and culminated in the cloning of the cDNAs for interferons $\alpha, \beta, \gamma$, IL2, TNF $\alpha$, and LT between 1981 and $1984 .^{1-3}$ This provided new tools to evaluate cytokine expression and regulation in rheumatoid synovium.
Rationale for anti-TNF $\alpha$ treatment (table 1)

We rapidly found that essentially all the cytokines were consistently expressed in RA tissue, although in different quantities, regardless of the stage of disease, or its treatment (reviewed by Feldmann et $a l^{4}$ ). This suggested to us that a key aspect of a chronic disease such as RA might be that, unlike experimentally induced cytokine production (for example, with mitogens or antigen), which is transient, diseased induced cytokine production is continuous. To test this idea, we cultured dissociated rheumatoid synovial cultures without extrinsic stimulation, and found that cytokine production in this in vitro model of RA was indeed spontaneous and prolonged, for over six days. $^{5}$ Moreover, we had discovered a system for asking questions about what drives the continuous endogenous cytokine production in RA synovium.

Our approach to this question, as immunologists, was to use neutralising antibodies. Based on the observations that IL1 induced the destruction of cartilage and bone, we studied the regulation of IL1 in the RA synovial cultures. At least half a dozen signals present in the RA synovium were known to regulate IL1, for example, IFN $\gamma, \mathrm{GM}-\mathrm{CSF}, \mathrm{TNF} \alpha$, immune complexes as well as IL1 itself, and so it was a surprise when we found that blocking $\mathrm{TNF} \alpha$ abolished IL1 bioactivity (fig 1$).{ }^{6}$ This was our first clue that blocking TNF $\alpha$ might be beneficial in RA, as it would also downregulate the equally pro-inflammatory cytokine, IL1. It led us to investigate the ability of anti-TNR $\alpha$ antibody to downregulate the production of other pro-inflammatory cytokines, and we found that GM-CSF, ${ }^{7}$ IL6, IL8 ${ }^{8}$ were also downregulated. This has led us to the concept that the pro-inflammatory cytokines, in a diseased tissue, were not independently regulated, but were coordinately regulated. One of the key coordinators was $\mathrm{TNF} \alpha$, to a lesser extent IL1.

The cytokine cascade concept is illustrated in figure 2, cytokine equilibrium in figure 3 .

Before the above studies, based on the presence and overlap in properties of the multitude of pro-inflammatory mediators, commonly termed "redundancy", it was thought that cytokines were poor therapeutic targets, based on the premise that if only one was blocked, the others would be sufficient to maintain the proinflammatory activities. Clearly it was imprac-
Correspondence to: Professor M Feldmann.
Kennedy Institu 1 Aspenlea Road Hammersmith London 

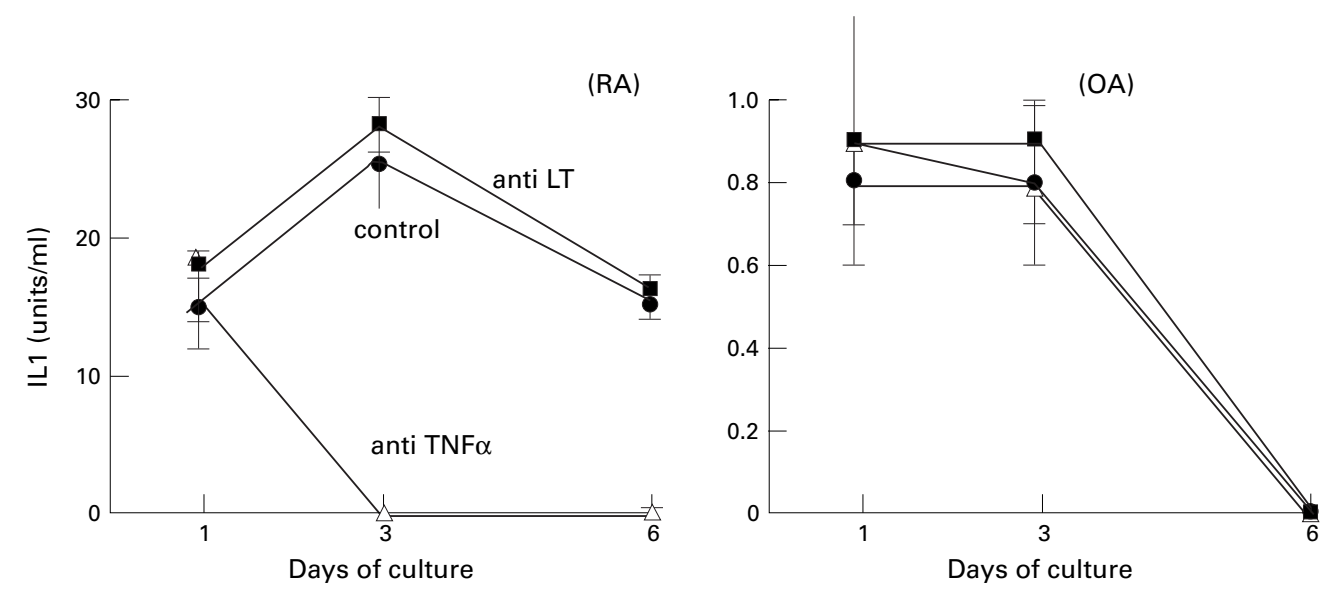

Figure 1 Inhibition of TNFa in rheumatoid synovium downregulated IL1: the first clue that TNFa was a therapeutic target. Modified and reprinted with permission from Brennan et al. Lancet 1989,ii:244-7.

tical to neutralise all the pro-inflammatory cytokines simultaneously.

To validate the concept that $\mathrm{TNF} \alpha$ was a prime therapeutic target in RA, two further types of studies were performed. One was to verify by immunohistology that in flash frozen biopsy specimens of RA synovium, TNF and TNF receptors were upregulated. ${ }^{9-11}$ The second was to evaluate anti-TNF $\alpha$ treatment in an animal model of RA, collagen induced arthritis. We and others found that anti-TNF $\alpha$ reduced joint inflammation and joint destruction, even if given in a therapeutic mode, that is after disease onset. ${ }^{12-14}$

\section{What regulates $\mathrm{TNF} \alpha$ synthesis by macrophages and rheumatoid synovium?} The work we pioneered in the rationale for anti-TNF $\alpha$ treatment and its validation in both open 15 and randomised placebo 16 controlled trials with the chimaeric anti-TNF $\alpha$ antibody of Centocor (cA2), now termed Infliximab or Remicade, has led to multiple confirmatory studies with other antibodies (for example, CDP571, Celltech/Bayer ${ }^{17}$ ) TNF-R Fc fusion proteins (Etanercept, Enbrel p75TNF-R Fc, Immunex $/ \mathrm{AHP}^{18}$ or lenercept, p55 TNF-R Fc, Roch $\left.^{19}\right)$, and more recently another antibody D2E7 (Knoll/CAT). ${ }^{20}$ Thus the principle of $\mathrm{TNF}$ as an effective therapeutic target is amply confirmed in clinical studies.

However TNF, as a multifunctional cytokine is needed in small amounts at times for normal

TIMP, TIMP-2

IL10, IL1ra, sTNF-R

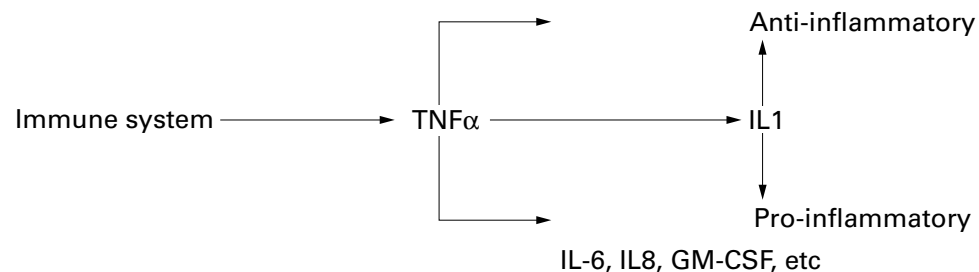

MMP-1, MMP-3

Figure 2 Cytokine cascade. By a multitude of blocking experiments with anti-TNFa and IL1 receptor antagonist, it was shown that in rheumatoid synovium both the pro-inflammatory and anti-inflammatory mediators are regulated by TNFa and IL1. Modified and reprinted with permission from Feldmann, Brennan and Maini. Cell 1996;85:307-10. immune function. Hence TNF knockouts are at risk of infection with intracellular microorganisms such as listeria. ${ }^{21}$ Is this the case in anti-TNF $\alpha$ treated patients? Clinical trial data so far suggest that with both Remicade and Enbrel the risk of infection is not higher than in the placebo treated controls. In theory this may not be the case for patients treated in the longer term. It is conceivable that the mechanism of $\mathrm{TNF} \alpha$ production in RA tissue may be different from that operating in the immune response to infections, and if so, it would be an intriguing possibility to block the "pathological" TNF $\alpha$ production in RA, but not "physiological" $\mathrm{TNF} \alpha$ in an immune response.

Another important reason for seeking to understand what drives TNF $\alpha$ production in macrophages and RA synovium is the fact that most orally available drugs act on intracellular signalling pathways. A key problem is how to study signalling in normal macrophages. These cells, like most normal cells do not transfect easily. Viruses are adapted to inserting their genes into cells, and getting them expressed, and thus we sought to use viruses to delivery inhibitory genes to macrophages.

By using adenoviruses, we have developed conditions that permit us to infect $>95 \%$ of normal macrophages. ${ }^{22}$ The TNF $\alpha$ promoter has numerous NF- $\mathrm{NB}$ sites, and so we used an adenovirus overexpressing $\mathrm{I} \kappa \mathrm{B} \alpha$, a natural inhibitor of $\mathrm{NF}-\kappa \mathrm{B}$ to evaluate the role of $\mathrm{NF}-\kappa \mathrm{B}$ in macrophage cytokine production. The results were interesting. For this single cytokine, for example, $\mathrm{TNF} \alpha$, the role of $\mathrm{NF}-\kappa \mathrm{B}$ varied markedly depending on the stimulus. LPS, PMA and UV light were markedly NF- $\kappa \mathrm{B}$ dependent (that is, blocked), but in contrast zymosan and anti-CD45 induced $\mathrm{TNF} \alpha$ were not blocked ${ }^{23}$ (fig 4). As NF-кB has been reported to prevent apoptosis, ${ }^{24}$ the above results with zymosan and anti-CD45 verify that the mechanism of $\mathrm{NF}-\kappa \mathrm{B}$ inhibition of TNF production was not by cell death. ${ }^{24}$ Of course this has been verified in other ways also, by MTT propidium iodide and dye exclusion assays. $^{22} 23$

These results indicated that the technique of adenoviral infection was suitable to use on RA synovial tissue, at least for analysing the 


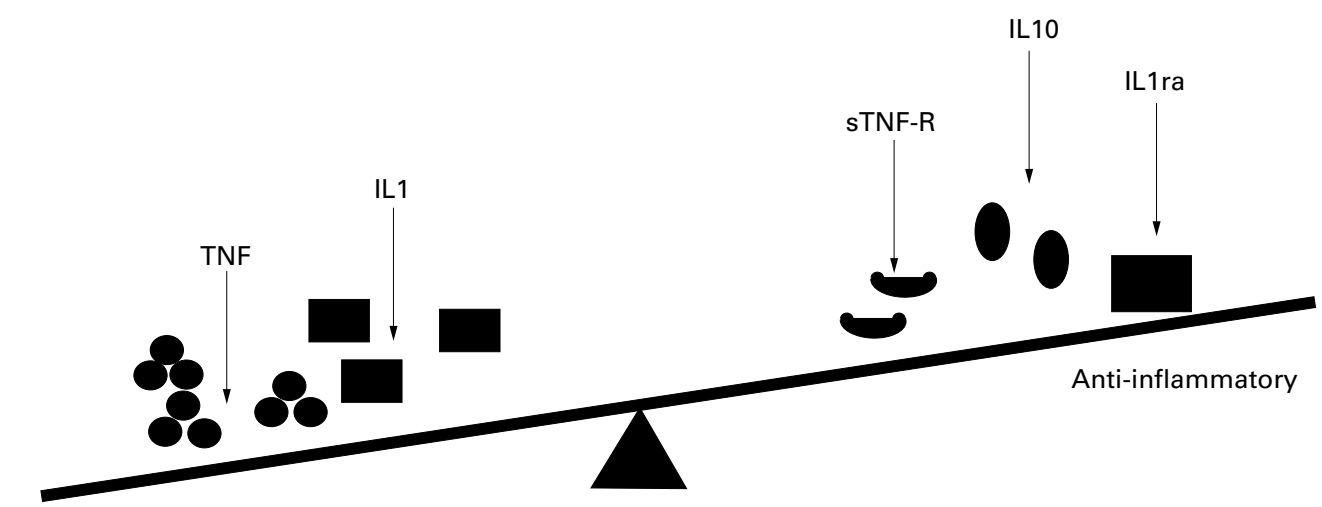

Pro-inflammatory

Figure 3 Cytokine disequilibrium. Modified and reprinted with permission from Feldmann, Brennan and Maini. Cell 1996;85:307-10.

macrophage TNR $\alpha$ production, which is the major, but not the only component of $\mathrm{TNF} \alpha$ production. As we wished to study cytokine production in the RA joint in detail, we first evaluated the infectability of some of the critical subsets of cells. Overall, $>90 \%$ of cells were infected, assessed using an adenovirus expressing $\beta$ galactosidase and flow cytometry. ${ }^{25}$ When subsets of cells were analysed by two colour flow cytometry, the results were interesting. As expected $\mathrm{CD} 14^{+} \mathrm{CD}^{-}$cells, chiefly macro-

\section{Table 1 Rationale for anti-TNFa treatment in rheumatoid arthritis}

1 Anti-TNF $\alpha$ downregulates production of IL1 and other pro-inflammatory mediators in rheumatoid synovial cultures ${ }^{678}$

$2 \mathrm{TNF} \alpha$ and TNF-receptors are upregulated in rheumatoid synovium. ${ }^{691011}$

3 Anti-TNF $\alpha$ antibody ameliorates arthritis in collagen induced arthritis. ${ }^{12} 13$ phages were infected $>95 \%, \mathrm{CD}_{1} 4^{-} \mathrm{CD}^{+}$cells, $\mathrm{T}$ lymphocytes were also infected at $>80 \%$. This was not predicted by prior reports, which reported the low infectability of $\mathrm{T}$ lymphocytes. CD $14^{-} \mathrm{CD} 3$ cells, chiefly fibroblasts, were as anticipated readily infected.

Having established that RA synovial cell mixtures were infectable by adenovirus, we set out to ascertain if the infection with $\operatorname{AdvI\kappa B} \alpha$ would change the cytokine profile produced. The results were clear cut. First to be assessed was $\mathrm{TNF} \alpha$, this was reduced by $70 \%$, mean of five synovial samples (fig 5). ${ }^{22}$ Subsequently other pro-inflammatory mediators were assessed. The results varied. IL6 production was blocked 90\%. However, IL1 production was different being reduced by only $40 \%$, and IL8

\section{Zymosan induced TNF $\alpha$}
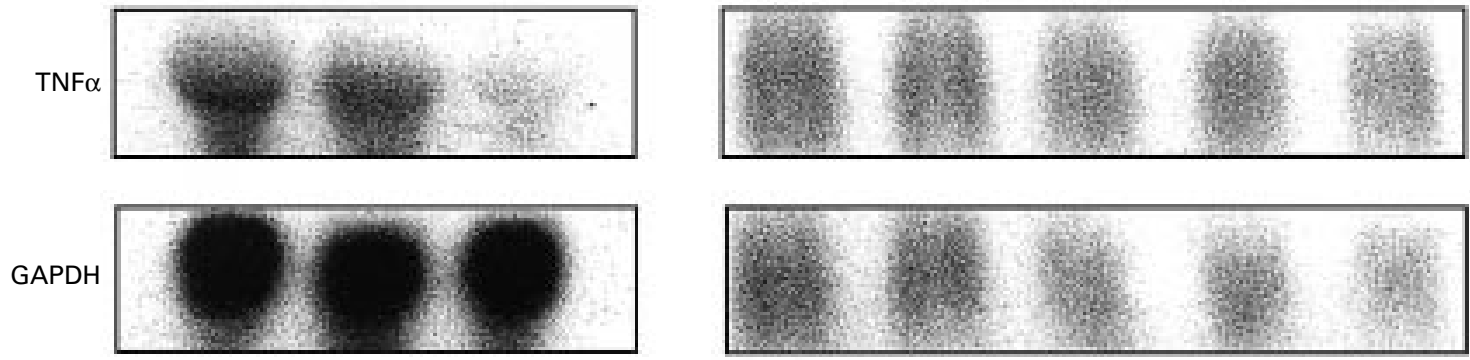

Uninfected Adv0 40:1 AdvlкB $\alpha$ 40:1

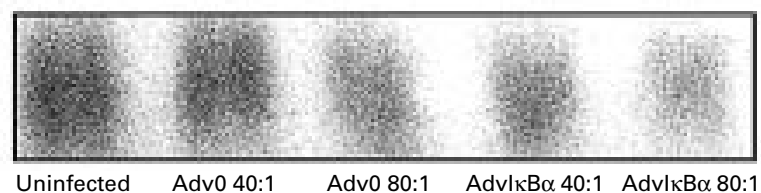

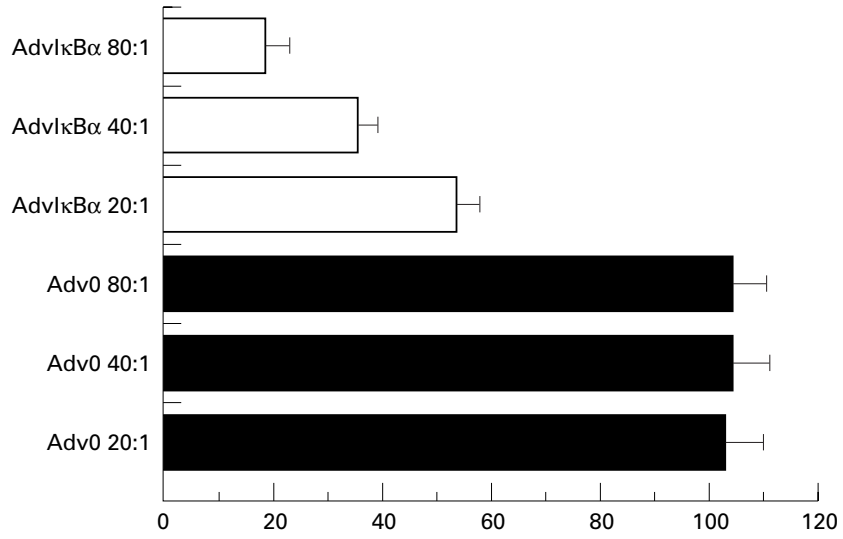

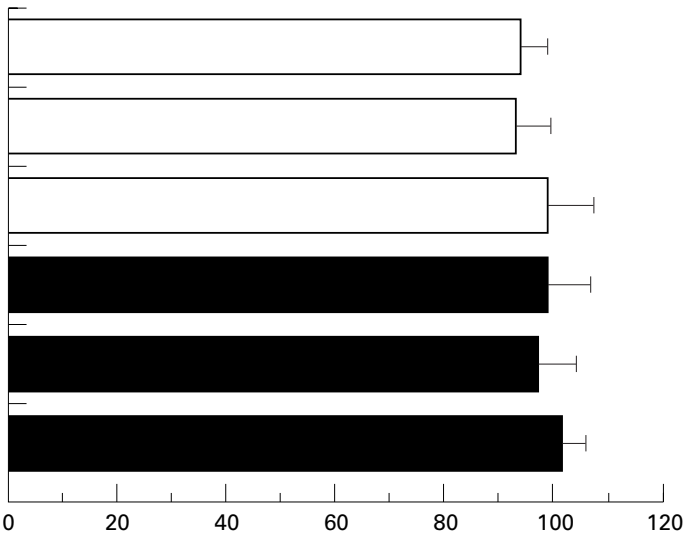

TNF $\alpha$ (percentage of response from uninfected cells)

Figure 4 The mechanism of TNFa production in macrophages depends on the stimulus. LPS is NF- $\kappa B$ dependent, zymosan is not. Modified from Bondeson et al. F Immunol 1999;162:2939-45. 

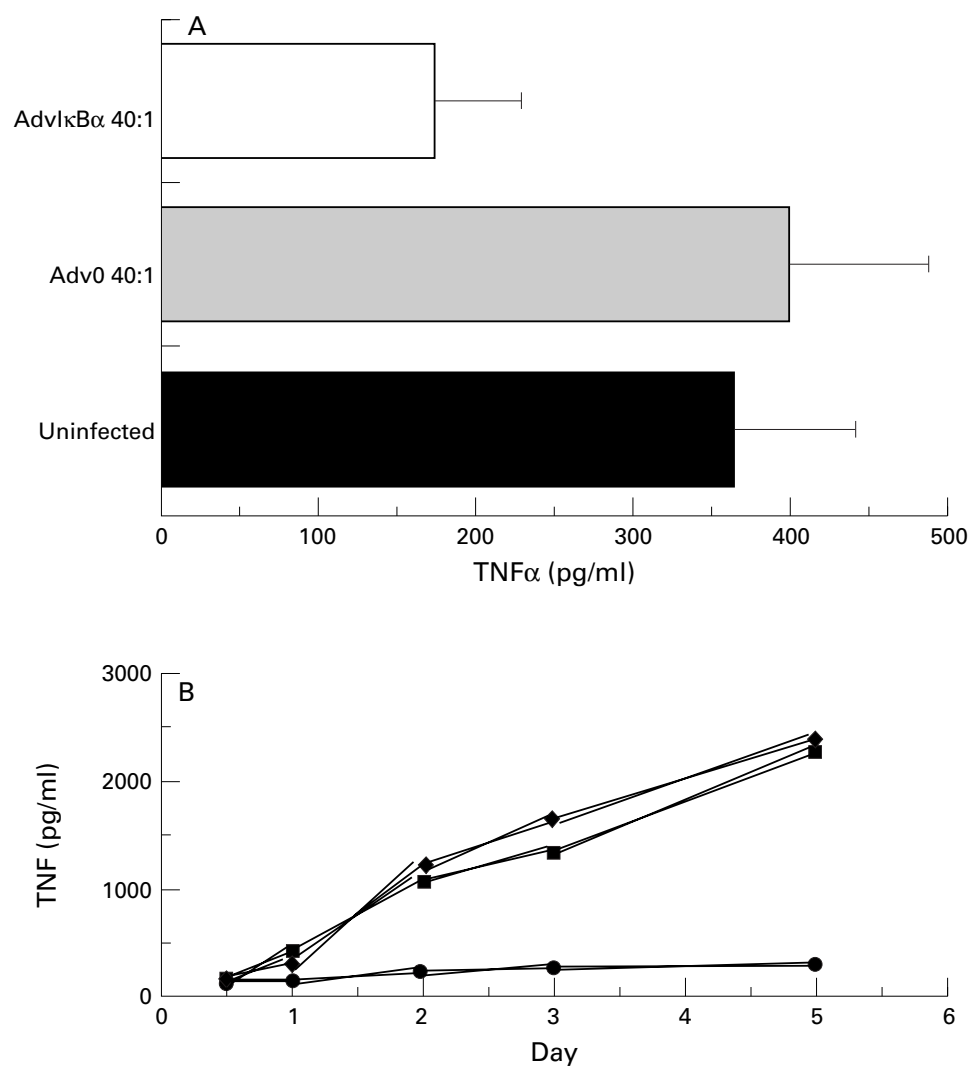

Figure 5 Rheumatoid synovial TNFa production is $N F-\kappa B$ dependent. Modified from Foxwell et al. Proc Natl Acad Sci 1998;95:8211-15.

production even more variably reduced perhaps $30-40 \%{ }^{25}$ These results emphasise that while $\mathrm{NF}-\kappa \mathrm{B}$ is an important transcription factor driving the inflammatory process, there are also other important pathways, the nature of which remain to be elucidated.

Evaluation of the effects of AdvIкB on the production of anti-inflammatory mediators led to quite different results. Thus there was minimal effects of over-expressed I $\mathrm{B} \alpha$ on IL10, IL1 receptor antagonist or IL11. There was a moderate diminution of soluble TNF-R, which could be restored by adding inflammatory mediators. $^{2325}$

In view of the fact that it is the disequilibrium of pro-inflammatory and antiinflammatory mediators that determines the "outcome" of an inflammatory process ${ }^{4}$ the effect of blocking NF- $\kappa \mathrm{B}$ in RA joints would thus seem to be very beneficial, as it diminishes pro-inflammatory mediators without reducing the anti-inflammatory.

Does $\mathrm{NF}-\kappa \mathrm{B}$ influence joint destructive processes? This is an interesting question, which is not fully understood. The conventional wisdom, based on analysis of the promoters of metalloproteinases (MMPs) is interpreted to suggest that $\mathrm{AP}-1$ is the critical regulator of matrix destructive MMPs. ${ }^{26}$ However, this concept has not been critically tested. We explored the effect of $\operatorname{AdvI} \kappa \mathrm{B} \alpha$ on the expression of MMP-1, MMP-3 and MMP-13 and their inducible inhibitor from dissociated rheumatoid synovial cultures. These studies showed that the production of MMPs, assessed by immunoassay was markedly downregulated by excess $\mathrm{I} \kappa \mathrm{B} \alpha$. In contrast, TIMP- 1 was upregulated. ${ }^{25}$ These results were verified by time course analysis over seven days and were stable. As pro-inflammatory cytokines upregulated MMPs these results by themselves do not establish that the effect is direct. It could be indirect, because of $\mathrm{I} \kappa \mathrm{B} \alpha$ downregulation of pro-inflammatory mediators. Indirect effects can, in principle be overcome by excess proinflammatory mediators. These experiments showed that there seemed to be both direct and indirect effects. ${ }^{25}$

\section{Conclusion}

TNR $\alpha$ blockade provides considerable benefit in RA. The exact means of doing so may not matter, as multiple antibodies, first cA2 (Remicade, Centocor) then CDP571 (Celltech/Bayer) have all yielded significant results, as have TNF receptors, Ig fusion proteins TNF-R p75 Fc (Enbrel, Immunex/ AHP), TNF-R p55 (Lenercept, Roche) or Amgen's monomeric TNF-R. These products, while all beneficial may yet differ, as the monoclonal antibodies are specific for $\mathrm{TNF} \alpha$, but the receptors can also block lymphotoxina. ${ }^{27}$ This may be more immunosuppressive.

We have reviewed here data that adenoviruses offer an efficient means of gene delivery and thus a powerful tool for defining what is really happening inside normal or pathological cells. The results indicate that blocking NF- $\kappa \mathrm{B}$ in rheumatoid joints would deliver all the benefits of TNF $\alpha$ blockade. How to do it in a safe and effective manner remains a challenge.

The majority of the work at the Kennedy Institute of Rheumatology is funded by the Arthritis Research Campaign. The clinitology is funded by the Arthritis Research Campaign. The clinia member of the Scientific Advisory Board of Centocor, Inc.

1 Goeddel DV, Yelverton E, Ullrich A, et al. Human leukocyte interferon produced by E. coli is biologically active. Nature interferon produced

2 Pennica D, Nedwin GE, Hayflick JS, et al. Human tumor necrosis factor: precursor structure expression and homology to lymphotoxin. Nature 1984;312:724-9.

3 Taniguchi T, Matsui H, Fujita T, et al. Structure and expression of a cloned cDNA for human interleukin-2. Nature 1983;302:305-10

4 Feldmann M, Brennan FM, Maini RN. Role of cytokines in rheumatoid arthritis. Ann Rev Immunol 1996;14:397-440. 5 Buchan G, Barrett K, Turner M, Chantry D, Maini RN, Feldmann M. Interleukin-1 and tumour necrosis factor mRNA expression in rheumatoid arthritis: prolonged production of IL-1 $\alpha$. Clin Exp Immunol 1988;73:449-55.

6 Brennan FM, Chantry D, Jackson A, Maini R, Feldmann M. Inhibitory effect of TNF $\alpha$ antibodies on synovial cell interleukin-1 production in rheumatoid arthritis. Lancet 1989;ii:244-7.

7 Haworth C, Brennan FM, Chantry D, Turner M, Maini RN, Feldmann $M$. Expression of granulocyte-macrophage colony-stimulating factor in rheumatoid arthritis: regulation by tumor necrosis factor- $\alpha$. Eur J Immunol 1991;21: 2575-9.

8 Butler DM, Maini RN, Feldmann M, Brennan FM. Modulation of proinflammatory cytokine release in rheumatoid synovial membrane cell cultures. Comparison of monoclonal anti-TNF $\alpha$ antibody with the IL-1 receptor antagonist. Eur Cytokine Network 1995;6:225-30

9 Saxne T, Palladino MA, Jr, Heinegard D, Talal N, Wollheim FA. Detection of tumor necrosis factor $\alpha$ but not tumor necrosis factor $\beta$ in rheumatoid arthritis synovial fluid and serum. Arthritis Rheum 1988;31:1041-5.

10 Brennan FM, Gibbons D, Cope AP, Reed B, Maini RN, Feldmann M. TNF- $\alpha$ and TNF receptor expression and regulation in rheumatoid arthritis. In: Balint G, Gomor B, Hodinka L, eds. Rheumatology, state of the art. Amsterdam: Elsevier Science Publishers, 1992:115-17.

11 Chu CQ, Field M, Feldmann M, Maini RN. Localization of tumor necrosis factor $\alpha$ in synovial tissues and at the cartilage-pannus junction in patients with rheumatoid cartilage-pannus junction in patients with

12 Thorbecke GJ, Shah R, Leu CH, Kuruvilla AP, Hardison $\mathrm{AM}$, Palladino MA. Involvement of endogenous tumour necrosis factor $\alpha$ and transforming growth factor $\beta$ during 
induction of collagen type II arthritis in mice. Proc Nat Acad Sci USA 1992;89:7375-9.

13 Williams RO, Feldmann M, Maini RN. Anti-tumor necrosis factor ameliorates joint disease in murine collagen-induced arthritis. Proc Nat Acad Sci USA 1992;89:9784-8.

14 Piguet PF, Grau GE, Vesin C, Loetscher H, Gentz R, Lesslauer W. Evolution of collagen arthritis in mice is arrested by treatment with anti-tumour necrosis factor (TNF) antibody or a recombinant soluble TNF receptor. Immunology 1992;77:510-14.

15 Elliott MJ, Maini RN, Feldmann M, et al. Treatment of rheumatoid arthritis with chimeric monoclonal antibodies to TNF $\alpha$. Arthritis Rheum 1993;36:1681-90.

16 Elliott MJ, Maini RN, Feldmann M, et al. Randomised double blind comparison of a chimaeric monoclonal antibody to tumour necro rheumatoid arthritis. Lancet 1994;344:1105-10.

17 Rankin ECC, Choy EHS, Kassimos D, et al. The therapeutic effects of an engineered human anti-tumour necrosis factor alpha antibody (CD571) in rheumatoid arthritis. Br J Rheumatol 1995;34:334-42.

18 Moreland LW, Baumgartner SW, Schiff $\mathrm{MH}$, et al. Treatment of rheumatoid arthritis with a recombinant human tumor necrosis factor receptor (p75)-Fc fusion protein. N Engl I Med 1997;337:141-7.

19 Cutolo M, Kirkham B, Bologna C, et al. Loading/ maintenance doses approach to neutralization of TNF by Lenercept (TN-FR55-IgGl, Ro45-2081) inpatients with rheumatoid arthritis treated for 3 months: results of a double-blind placebo controlled phase II trial. Arthritis Rheum 1996;39:S243.

20 Schattenkirchner M, Kruger K, Sander O, et al. Efficacy and tolerability of weekly subcutaneous injections of the fully human anti TNF antibody D2E7 in patients with rheumatoid arthritis - Results of a phase 1 study. Arthritis Rheum 1998;41:S57.

21 Marino MW, Dunn A, Grail D, et al. Characterization of umor necrosis factor-deficient mice. Proc Natl Acad Sci USA 1997;94:8093-8.

22 Foxwell BMJ, Browne K, Bondeson J, et al. Efficient adenoviral infection with $\mathrm{I} \kappa \mathrm{B} \alpha$ reveals that $\mathrm{TNF} \alpha$ production in rheumatoid arthritis is NF- $\kappa \mathrm{B}$ dependent. Proc Natl Acad Sci USA 1998;95:8211-15.

23 Bondeson J, Brown KA, Brennan FM, Foxwell BMJ, Feldmann $M$. Selective regulation of cytokine induction by adenoviral gene transfer of I $\mathrm{B} \alpha$ into human macrophages: LPS induced but not zymosan induced, pro-inflammatory cytokines are inhibited, but IL-10 is NFkb independent. J Immunol 1999;162:2939-45.

24 Wang C-Y, Mayo MW, Baldwin AS. TNF- and cancer herapy-induced apoptosis: potentiation by inhibition of NF-кB. Science 1996;274:784-7.

25 Bondeson J, Foxwell BMJ, Brennan FM, Feldmann M. Defining therapeutic targets by using adenovirus: blocking NF-KB inhibits both inflammatory and destructive mechanisms in rheumatoid synovium but spares anti1999;96:5668-73.

26 Fini ME, Cook JR, Mohan R, Brinckerhoff CE. Regulation of matrix metalloproteinase gene expression. In: Parks WC, Mecham RP, eds. Matrix metalloproteinases. San Diego: Academic, 1998:299-356.

27 Smith CA, Davis T, Anderson D, et al. A receptor for tumor necrosis factor defines an unusual family of cellular and viral proteins. Science 1990;248:1019-23. 